\title{
Phenotypic plasticity associated to environmental hypoxia in the neotropical serrasalmid Piaractus mesopotamicus (Holmberg, 1887) (Characiformes: Serrasalmidae)
}

\author{
María Alejandra Fernández-Osuna ${ }^{1}$ and Pablo Augusto Scarabotti ${ }^{2}$
}

\begin{abstract}
Many South American characid fishes develop reversible dermal protuberances in the jaws to optimize aquatic surface respiration (ASR) during hypoxia. To date, basic aspects of this adaptation remain unknown, mainly due to the scarcity of experimental studies. In laboratory experiments, we determined time necessary for the complete formation and reversion of these structures in Piaractus mesopotamicus, and studied comparatively behavioral, morphological, and respiratory responses along gradients of dissolved oxygen (DO) concentration. Morphological changes during hypoxia consisted in dermal protuberances of lower lip, anterior border of maxillary and distal border of opercular valve, increasing the known number of structures modified. These structures developed completely in less than 6 hours and reversed in less than 3 hours. Most of observed traits showed a logistic response curve with threshold DO values between 0.90 and $2.70 \mathrm{mgL}^{-1}$. Respiratory frequency and opercular valve development showed similar threshold values above the level of tolerance of DO, whereas ASR and dermal protuberances of the jaws showed threshold values below this level. This observation supports the functional link between these groups of behavioral and morphological traits. This study demonstrates that this species is able to modify reversibly portions of the respiratory system to optimize responses to hypoxia.
\end{abstract}

Muchos peces carácidos sudamericanos desarrollan protuberancias dérmicas reversibles en las mandíbulas para optimizar la respiración acuática superficial (RAS) durante la hipoxia. Actualmente, aspectos básicos de esta adaptación permanecen desconocidos, principalmente debido a la escasez de estudios experimentales. En experiencias de laboratorio, determinamos el tiempo necesario para el desarrollo y la reversión completos de estas estructuras en Piaractus mesopotamicus, y estudiamos comparativamente respuestas conductuales, morfológicas, y respiratorias en un gradiente de concentración de oxígeno disuelto (OD). Los cambios morfológicos durante la hipoxia consistieron en protuberancias dérmicas del labio inferior, el borde anterior del maxilar, y el borde distal de la válvula opercular, incrementando el número conocido de estructuras modificadas. Éstas se desarrollaron completamente en menos de 6 horas y se revirtieron en menos de 3 horas. La mayoría de los rasgos observados siguieron una curva de respuesta logística, con valores críticos entre 0,90 y $2,70 \mathrm{mgL}^{-1} \mathrm{de}$ OD. La frecuencia respiratoria y el desarrollo de la válvula opercular presentaron valores críticos similares ubicados por encima del nivel de tolerancia al OD, mientras que la RAS y las protuberancias dérmicas mandibulares presentaron críticos por debajo de dicho nivel. Estas observaciones apoyan la relación funcional existente entre estos grupos de rasgos conductuales y morfológicos. Este estudio demuestra que esta especie puede modificar reversiblemente porciones del sistema respiratorio para optimizar las respuestas a la hipoxia.

Keywords: Aquatic surface respiration, Characiformes, Dermal lip protuberances, Reaction norm, River floodplains.

\section{Introduction}

Phenotipic plasticity is the ability of an organism to modify their phenotype in response to changes in the environment (Whitman \& Agrawal, 2009). It has been proposed as a mechanism to exploit heterogeneous or changing environments (Lande, 2014). In this context, the environmental heterogeneity driven by the seasonal flood pulse in large river floodplains (Junk, 1997) is expected to favor phenotypic plasticity. Extreme temporal fluctuations in dissolved oxygen (DO) are common in these environments, generating a wide range of adaptations and plastic responses to cope with hypoxia (Almeida-Val et al., 2006; ChippariGomes et al., 2005; Rutjes, 2006; Pollock et al., 2007; Chapman \& McKenzie, 2009). Hypoxic areas provide food and refuge to adult and juvenile fish, conferring selective

${ }^{1}$ Centro de Investigaciones Científicas y Transferencia de Tecnología a la Producción (CONICET), Dr. Materi s/n, (3100) Paraná, Argentina. alefosuna@hotmail.com

${ }^{2}$ Instituto Nacional de Limnología (CONICET-UNL), Ciudad Universitaria, (3000) Santa Fe, Argentina. pscarabotti@gmail.com (corresponding author) 
advantages to species able to colonize these environments (Domenici et al., 2007; Yamanaka et al., 2007; Anjos et al., 2008; Reid et al., 2013). Given that DO exhibit wide and fine-grained variation along the time, and responses to hypoxia are generally costly in adaptive terms (Chapman et al., 2008), evolution should favor rapid trait reversal when oxygen conditions are reestablished. However, this aspect has been poorly explored for hypoxia-induced traits (e.g. Nilsson et al., 2012).

In aquatics environments, DO acts like a resource in the way that organisms can opt for alternative sources and different types of acquisition (Kramer, 1987). Most of species inhabiting temporally hypoxic environments respond to hypoxia using behavioral strategies, like aquatic surface respiration (ASR) (Almeida-Val et al., 2006; Soares et al., 2006; Chapman \& McKenzie, 2009; Morosawa, 2011; Urbina et al., 2011). ASR is a widespread mechanism in fishes to exploit the oxygen available in the thin layer of surface water, where rapid diffusion maintains high oxygen concentrations even during hypoxia (Lewis, 1970; Kramer \& Mehegan, 1981). Many South American characiform species optimize the performance of ASR developing reversible dermal protuberances in the jaws that improve the influx of surface water into the mouth (Winemiller, 1989; AlmeidaVal et al., 2006; Florindo et al., 2006; Scarabotti et al., 2009, 2011). Protuberances are edematous structures (Saint-Paul \& Bernardinho, 1988; Saint-Paul \& Soares, 1988; Scarabotti et al., 2011), which develops in 2 to 4 hours and revert completely when oxygen conditions are reestablished (Branson \& Hake, 1972; Braum \& Junk, 1982; Saint-Paul \& Bernardinho, 1988). Protuberances were described formerly for the inferior jaw (Braum \& Junk, 1982; Winemiller, 1989), although recent field studies suggest that a wider range of structures can exhibit plasticity during hypoxia (Scarabotti el al., 2009, 2011). Given that most cases of morphological plasticity are irreversible and long term, this adaptation constitutes a very particular case of rapid and reversible morphological change coupled to a behavioral short term response.

All studies which induced protuberances development in laboratory have used extreme hypoxia and normoxia states as treatments, without considering the effect of intermediate values of DO (Braum \& Junk, 1982; SaintPaul \& Bernardinho, 1988; Val, 1996; Sundin et al., 2000; Florindo et al., 2006). Critical DO concentrations were determined in field studies with values oscillating between 1.30 and $1.75 \mathrm{mgL}^{-1}$, but a very high variability was observed in the response, presumably associated to environmental heterogeneity or individual differences (Winemiller, 1989; Scarabotti et al., 2011). For this reason, the response curve of dermal protuberances to DO has not been adequately established to date.

In the context of phenotypic plasticity, the function which describes the relationship between the development of a trait and the environmental variation is called reaction norm (Oomen \& Hutchings, 2015). The shape of the reaction norm of a trait can inform about selective forces driving their evolution (Gibert et al., 1998; Oomen \& Hutchings 2015). Finally, the functional link between protuberance formation and ASR has been mentioned in several works, but there are no studies with simultaneous quantitative analysis of behavioral and morphological traits to observe relationships and identify the functions of these traits. Then, adequately designed experiments are needed to resolve these questions.

In this study, we used the characiform fish Piaractus mesopotamicus (Holmberg, 1887), a species typical of frequently hypoxic floodplain environments of South America, which exhibit a series of morphological and physiologicaladaptations to survive at low DOconcentrations (Rantin et al., 1998; Saint-Paul \& Bernardinho, 1988; Severi et al., 1997; Kalinin et al., 2000; Leite et al., 2007). In a series of laboratory experiments we studied comparatively behavioral, morphological, and respiratory responses of P. mesopotamicus along a gradient of DO concentrations. Our objectives were 1) to determine the degree and velocity of development and reversion of several morphological traits, 2) to describe the shape of response of behavioral, morphological and respiratory responses to hypoxia and 3) to compare the degree of plasticity of these traits.

\section{Material and Methods}

\section{Experimental animals and laboratory conditions.} Juveniles of Piaractus mesopotamicus (33.54$75.50 \mathrm{~g} ;{ }^{-} \mathrm{x}=52.73 \mathrm{~g}$ and $\left.93-123 \mathrm{~mm} \mathrm{SL} ;{ }^{-} \mathrm{x}=110 \mathrm{~mm}\right)$ were kept in $100 \mathrm{~L}$ aquaria with aged dechlorinated tap water, at $25^{\circ} \mathrm{C}$ and an artificial photoperiod of 14:10 hours of light: darkness. They were fed with floating pellet food until 48 hours before experiments.

In each treatment, an individual $68 \times 23 \times 28 \mathrm{~cm}$ glass aquarium was kept to a specific DO concentration. Oxygen concentrations were obtained by the addition of small quantities of sodium sulfide $\left(\mathrm{Na}_{2} \mathrm{SxH}_{2} 0\right.$, Anedra ${ }^{\circledast}$, with a grade of $60.8 \% \mathrm{Na}_{2} \mathrm{~S}$ by weight) to the water (Soares \& Junk, 2000; Soares et al., 2006) 24 hours before the placement of fish in aquaria. We added approximately $0.16 \mathrm{mgL}^{-1}$ of $\mathrm{Na}_{2} \mathrm{~S}$ to reduce DO in $1 \mathrm{mgL}^{-1}$. To avoid re-oxygenation, aquaria were hermetically sealed with plastic sheets. The period of 24 hours was sufficient to reach stable DO concentrations for experiments and to oxidize the sulfide added to sulfite and sulfate products (Cline \& Richards, 1969; Chen \& Morris, 1972). This procedure reduced the potential effects of the direct addition of sulfur salts on fish health. Other authors using this methodology (Soares \& Junk, 2000; Soares et al., 2006) reported similar swimming behavior and ASR responses to that reported in studies using other methods of reducing DO.

DO concentrations were continuously monitored with an YSI model 85 DO probe (Yellow Spring Instruments), calibrated each day previously to the experiments. To minimize disturbances, we placed a black plastic curtain at $30 \mathrm{~cm}$ of aquaria, and performed observations trough a small opening $(5 \times 10 \mathrm{~cm})$. 
We carried out a first experiment to observe the degree and velocity of development and reversion of dermal structures in conditions of extreme hypoxia and normoxia; and a second experiment to determinate the shape of response and the comparative plasticity of behavioral, morphological and respiratory variables along a gradient of DO concentrations.

Experiment 1. Degree and velocity of development and regression of morphological traits. A total of 11 fish were kept individually in different aquaria and exposed for 9 hours to (mean $\pm \mathrm{SD}$ ) $0.49 \pm 0.30 \mathrm{mgL}^{-1}$ (extreme hypoxia) (Braum \& Junk, 1982; Saint-Paul \& Soares, 1988; Saint-Paul \& Bernardinho, 1988) and subsequently placed at another aquarium with 6-7 $\mathrm{mgL}^{-1}$ of DO (normoxia) for 3 additional hours. Fish were gently removed from the aquaria and photographed at $0,3,6,9,10$ and 12 hours of experiment, to track changes in shape and area of dermal structures. To prevent stress, animals were manipulated with small dipnets as carefully as possible. Fish exposed to chronic hypoxia generally swam quietly near the water surface and showed little escape and struggle behavior during the process of capture and transference. Previously to the manipulation to take photographs, fish were placed in a solution of $300 \mathrm{mg} / \mathrm{L}$ of lidocaine until the first signs of loss of equilibrium (approximately $60 \mathrm{sec}$ ). Lidocaine has been used to reduce behavioral and physiological painrelated responses in marine and freshwater fish with no observable side effects (Park et al., 2011; Sneddon, 2012).

We evaluated the development of three different structures, 1) the occlusive surface of the anterior dermal portion of the lower jaw, 2) the dermal portion of the anterior margin of maxillary bone and, 3) the lateral area of the opercular valve, a dermal fold associated to the posterior margin of the operculum. Before taking the photographs, each anatomic structure was laid on the surface of a glass, placed within the aquarium, with the purpose of guaranteeing a plain area for the measurements. Photographs were taken using a camera Canon PowerShot SX130IS with the Macro setting at a focus distance of $2 \mathrm{~cm}$.

Experiment 2. Behavioral, morphological and respiratory responses along the DO gradient. In this experiment, fish were placed individually in aquaria at a fixed DO concentration along a gradient between 0.35 and 6.45 $\mathrm{mgL}^{-1}$ for 6 hours. A total of 40 fish were used along this gradient, assigning randomly five fish at concentrations belonging to the following eight DO intervals: $0.35-0.63$; $0.68-1.2 ; 1.32-1.7 ; 1.78-2.18 ; 2.4-2.7 ; 2.85-3.63 ; 3.82-4.33$ and 5.47-6.57.

The behavioral and respiratory variables were analyzed directly by visual observations. To minimize disturbances, observations were performed trough small openings $(5 \times 10 \mathrm{~cm})$ made in the curtain in front of each aquaria. Behavioral and respiratory variables were measured during the last 3 hours of experience, at hourly intervals, giving the animals three hours for acclimation.
The respiratory frequency (RF) was determined from the direct observation of opercular movements (Saint-Paul \& Bernardinho, 1988; Chapman et al., 1995). To measure the locomotory activity of the animal, we measured vertical (VM) and horizontal movements (HM), using a 5 x $5 \mathrm{~cm}$ grid, drawn in the aquarium wall and counted the number of horizontal and vertical lines crossed by the medial line of fish eye during a 2 min period (Weber \& Kramer, 1983). ASR frequency was calculated, measuring the percentage of time that the fish were in contact with water surface within a 2 min period. Morphological measurements were made on photographs taken at the beginning and at the end of the experiences.

Measurement of morphological variables on photographs. Fish were photographed underwater positioning the surface of each dermal structure on a scaled glass slide placed on the wall of a small aquarium. The software Image $\mathrm{J}^{\circledR}$ was used to make the measurements on the photographs, tracing polygons on the outlines of each structure to determine its area.

Statistical analysis. In experiment 1 , morphological measurements were made on the same individuals on different times. Then, we used a repeated measures ANOVA to determine differences in the development of the structures along the hypoxic and normoxic periods $(0,3,6,9$ hours of hypoxia, and 1, 3 hours of normoxia). This analysis accounted for differences in the degree of responses between individuals, because individuals are taken as blocks in this analysis.

In experiment 2, we calculated the degree of morphological development as the ratio between the morphological measurements at the beginning and at the end of the experiment for each fish. The degree of response for behavioral and respiratory variables was calculated as the mean of the three observations done in the last three hours of the experience.

The shape of the response of the phenotypic traits analyzed respect to DO was described by a four parameter logistic function. This function is useful to describe the relationship between the phenotype $(p)$ and the environment $(e)$ for threshold plastic responses as follows (Gibert et al., 1998):

$$
p=P m+\frac{\left(P_{M}-P_{m}\right)}{\left(1+\frac{e}{E_{c}}\right)^{S}}
$$

where $P_{m}$ and $P_{M}$ are minimum and maximum asymptotic phenotypic values, $E_{c}$ is the value of the environmental variable at the inflection point and $S$ is the slope at the inflection point. These parameters are of key importance because they allow the estimation of the range of phenotypic variability $\left(P_{M^{-}} P_{m}\right)$, the critical DO concentration necessary for the response $\left(E_{c}\right)$, and the characterization of the response as gradual or abrupt $(S)$. 
To determine if the adjustment to the logistic curve varied along the DO gradient evaluated, we carried out a regression of the residuals of the logistic function for lower lip variable respect to DO concentrations. This analysis allowed us to determine if morphological variability increases or not around the critical environmental value $(E)$ as in other morphological traits exhibiting logistic reaction norms (Del Giudice, 2006).

Comparisons of plasticity among behavioral, morphological, and respiratory variables were made using the coefficient of variation $(\mathrm{CV})$ for each trait across the DO gradient. This index allows comparisons of plasticity among traits with different units (e.g. behavioral and morphological) and scales (Scheiner \& Goodnigth, 1984). On the first step, we calculated the mean value of each trait. Then, we grouped the 40 measurements of each trait within the eight DO intervals along the gradient, with 5 measurements each one. We randomly selected one observation of each interval without reposition and calculated the first CV. This process was repeated five times, resulting in five $\mathrm{CV}$ per variable (see Relyea, 2001). Finally, we applied an ANOVA to determine differences in the mean $\mathrm{CV}$ among variables.

\section{Results}

Development and reversion velocity in morphological traits. Morphological traits showed rapid and significant increases in size in response to hypoxia followed by a rapid reversion when fish were passed to normoxic conditions (Figs. 1a-c, 2). Lower lip ( $\left.\mathrm{F}=41.57 ; \mathrm{P}=1.15 \times 10^{-16}\right)$ achieved the greatest size at the 6 hours, showing an increase of $190 \%$ (Fig. 1a). The maxillary $\left(\mathrm{F}=28.6 ; \mathrm{P}=1.43 \times 10^{-13}\right)$ reached its maximum development at 6 hours with $37 \%$ of increase (Fig. 1b). Opercular valve ( $\left.\mathrm{F}=9.638 ; \mathrm{P}=1.74 \times 10^{-6}\right)$ showed the maximum development ( $40 \%$ of increase) at 3 hours without increments in subsequent observations (Fig. 1c). Normoxia conditions triggered rapid reversal of all morphological structures at the first hour, reaching typical size at 3 hours (Fig. 1).

Behavioral, morphological and respiratory responses along the dissolved oxygen gradient. Morphological, behavioral and respiratory variables showed clear threshold responses respect to DO variation. Four parameter logistic function adequately described the variation in all traits except for horizontal and vertical movements (Figs. 3-4). Variables with logistic responses showed critical DO values between 0.91 and $2.70 \mathrm{mgL}^{-1}$ (Table 1). Interestingly, functionally related morphological and behavioral traits showed similar $E_{c}$ values: lower lip and maxillary showed similar critical values respect to ASR, whereas opercular valve showed a similar critical value respect RF (Table 1; Fig. 3). The slope $(S)$ of the responses indicated that percentage of time at the surface was the variable with the more abrupt response, whereas RF was the variable with the most gradual response (Table 1; Fig. 4).

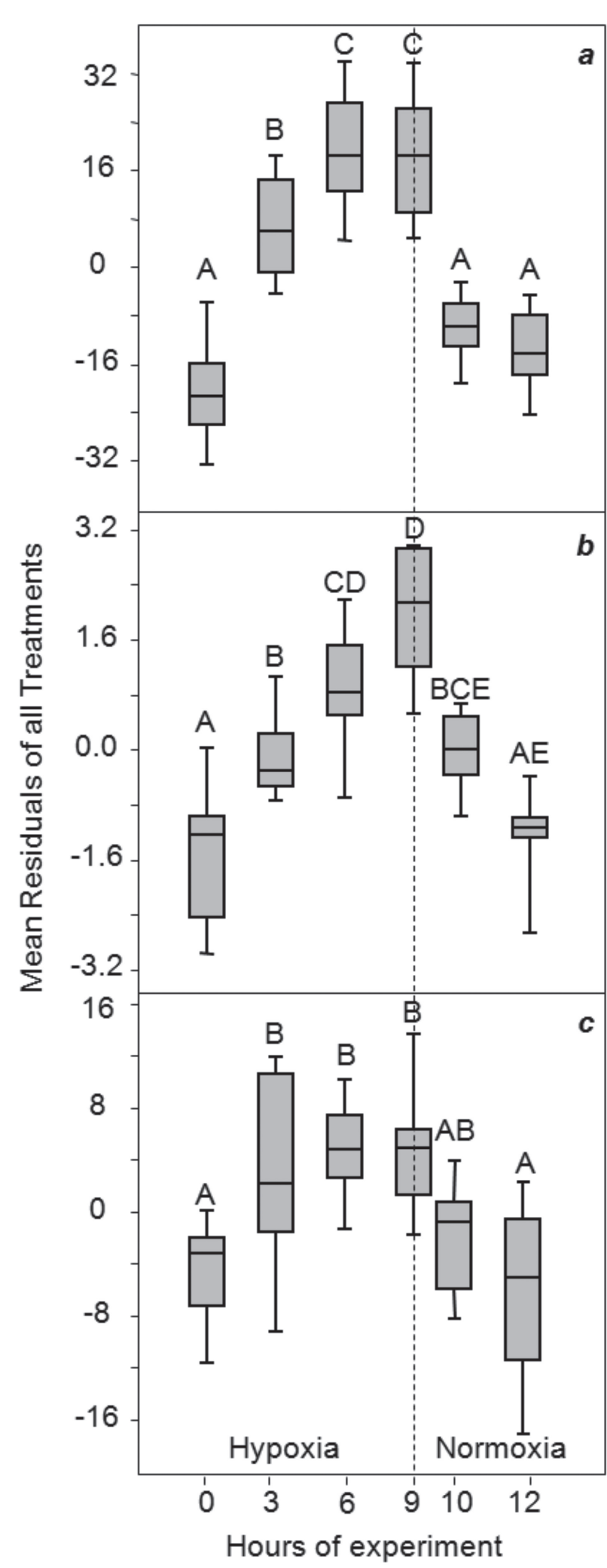

Fig. 1. Development and reversion of the three morphological variables exposed to nine hours of hypoxia, followed by three hours of normoxia in Piaractus mesopotamicus. (a) lower lip, (b) maxillary, and (c) opercular valve. Capital letters above box plots indicate groups in multiple comparisons (Tukey's tests) after repeated measures ANOVA. 
Normoxia

Hypoxia

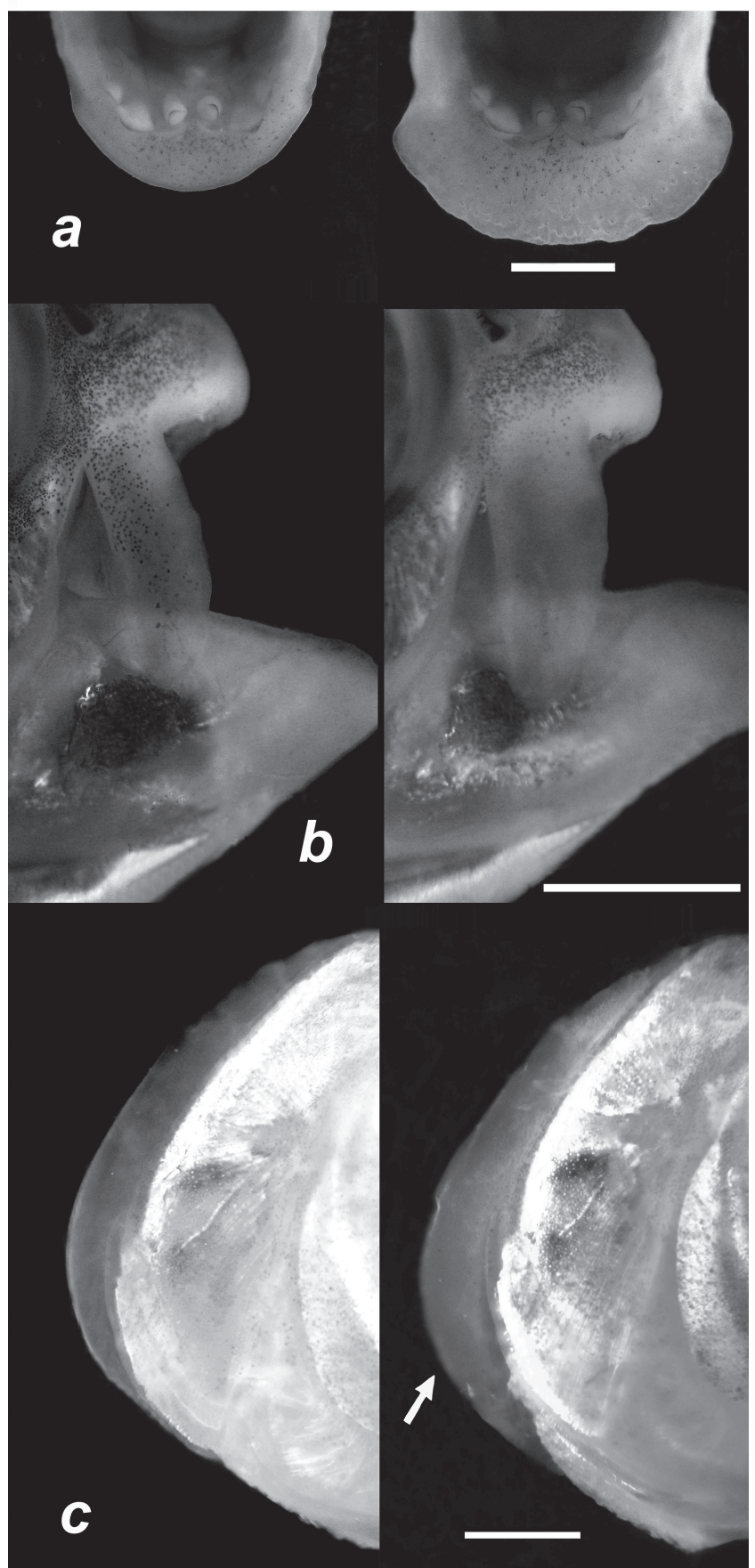

Fig. 2. Photographs showing increases in size of the three morphological traits of Piaractus mesopotamicus analyzed exposed to extreme hypoxia: (a) lower lip, (b) maxillary, and (c) opercular valve. White arrow indicates the area where the expansion of dermal tissue occurred.

Respiratory frequency increased almost three-fold along the gradient of DO, exhibiting values of $P_{m}$ and $P_{M}$ of 45 and 131 breaths $\mathrm{min}^{-1}$ respectively. Horizontal and vertical movements showed a high degree of variation along the DO gradient without sharp tendencies, but some patterns can be mentioned. Mean HM increased gradually when DO reduced, and all fish moved at approximately $225 \mathrm{~cm} \cdot \mathrm{min}^{-1}$ below $1.00 \mathrm{mgL}-1$, when fish performed ASR. Vertical movements reduced markedly below $1.00 \mathrm{mgL}^{-1}$ and remained below $25 \mathrm{~cm} \cdot \mathrm{min}^{-1}$ during ASR.

The residuals of the logistic function for lower lip variable indicated an increase in the dispersion around the critical value, peaking at $1.00 \mathrm{mgL}^{-1}$, and decreasing at lower DO concentrations.

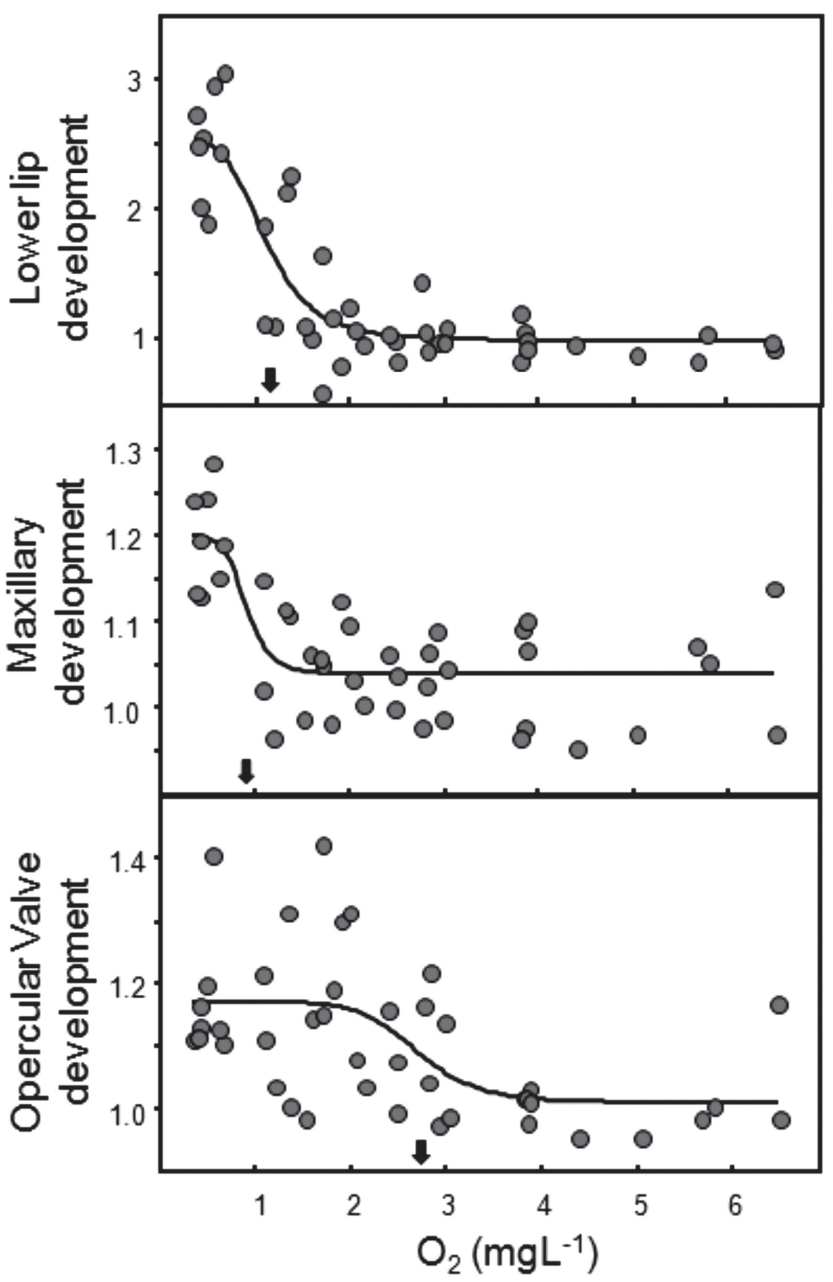

Fig. 3. Response curves of three morphological variables of Piaractus mesopotamicus (proportion of increase) respect to dissolved oxygen gradient. Black arrow indicates the DO concentration determined for the inflection point of the reaction norm.

Plasticity comparisons. The ANOVA applied to CVs showed significant differences in the degree of plasticity among behavioral, morphological and respiratory variables $\left(\mathrm{F}=69.83 ; \mathrm{P}=2.66 \times 10^{-22}\right)$ (Fig. 5). Aquatic surface respiration was the most plastic variable whereas the opercular valve and the maxillary were the less plastic. Among morphological variables, lower lip was much more plastic than the opercular valve and the maxillary. 
Hypoxia-induced plasticity in Piaractus mesopotamicus

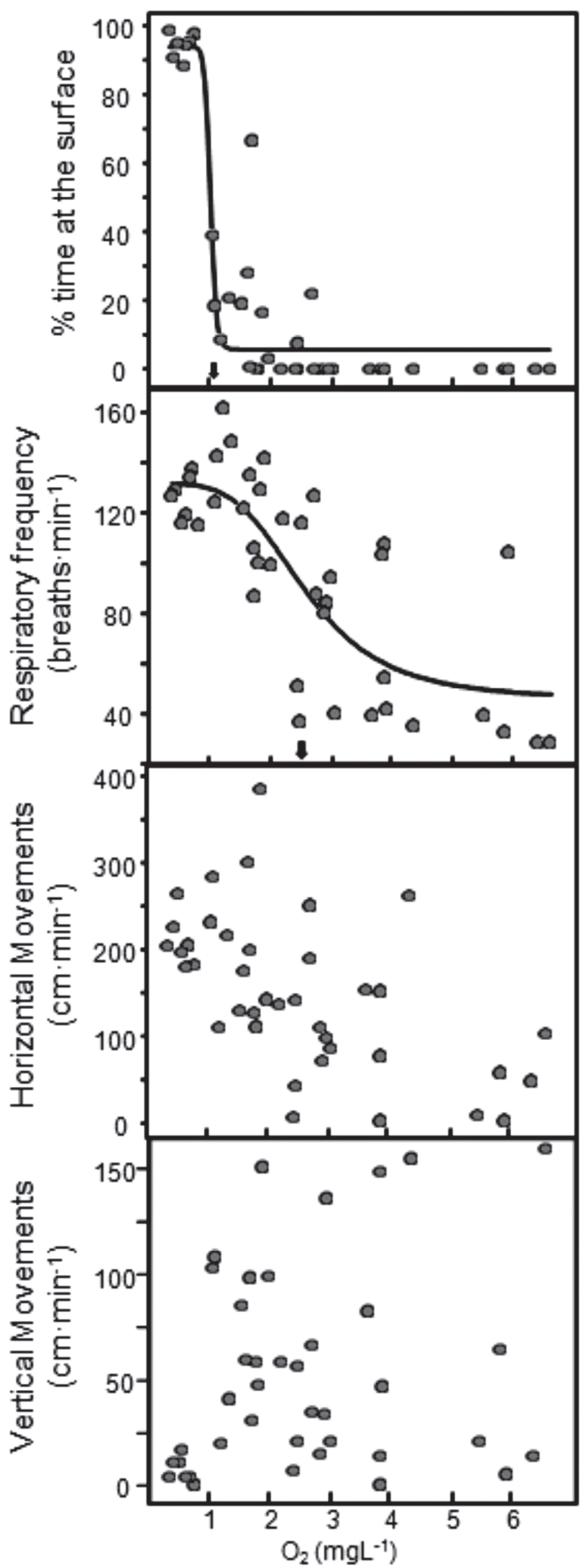

Fig. 4. Response curves of behavioral and respiratory variables of Piaractus mesopotamicus respect to dissolved oxygen gradient. Black arrow indicates inflection point given by the four parameters logistic function. The curve fitted to data points is not shown for horizontal and vertical movements due to the great dispersion.
Table 1. Parameters of the logistic reaction norm describing the variation of morphological, behavioral and respiratory variables of Piaractus mesopotamicus respect to DO variation. $\mathrm{P}_{\mathrm{m}}$ : Minimum phenotypic value; PM: Maximum phenotypic value; $\mathrm{E}_{\mathrm{c}}$ : Critical environmental value (DO concentration) at the inflection point; S: slope at the inflection point and; \%ASR: percentage of time performing ASR.

\begin{tabular}{|c|c|c|c|c|}
\hline & \multicolumn{4}{|c|}{ Parameters of the reaction norm } \\
\hline & $\mathrm{P}_{\mathrm{m}}$ & $\mathrm{P}_{\mathrm{M}}$ & $\mathrm{E}_{\mathrm{c}}$ & $\mathrm{S}$ \\
\hline \multicolumn{5}{|c|}{ Behavioral variable } \\
\hline$\% A S R$ & 6.07 & 94.16 & 1.02 & 22.16 \\
\hline \multicolumn{5}{|c|}{ Morphological variables } \\
\hline Lower Lip & 0.98 & 2.54 & 1.11 & 4.50 \\
\hline Maxillary & 1.04 & 1.20 & 0.91 & 7.34 \\
\hline Opercular Valve & 1.01 & 1.17 & 2.70 & 8.66 \\
\hline \multicolumn{5}{|c|}{ Respiratory variable } \\
\hline Respiratory Frequency & 45.41 & 131.83 & 2.55 & 3.93 \\
\hline
\end{tabular}

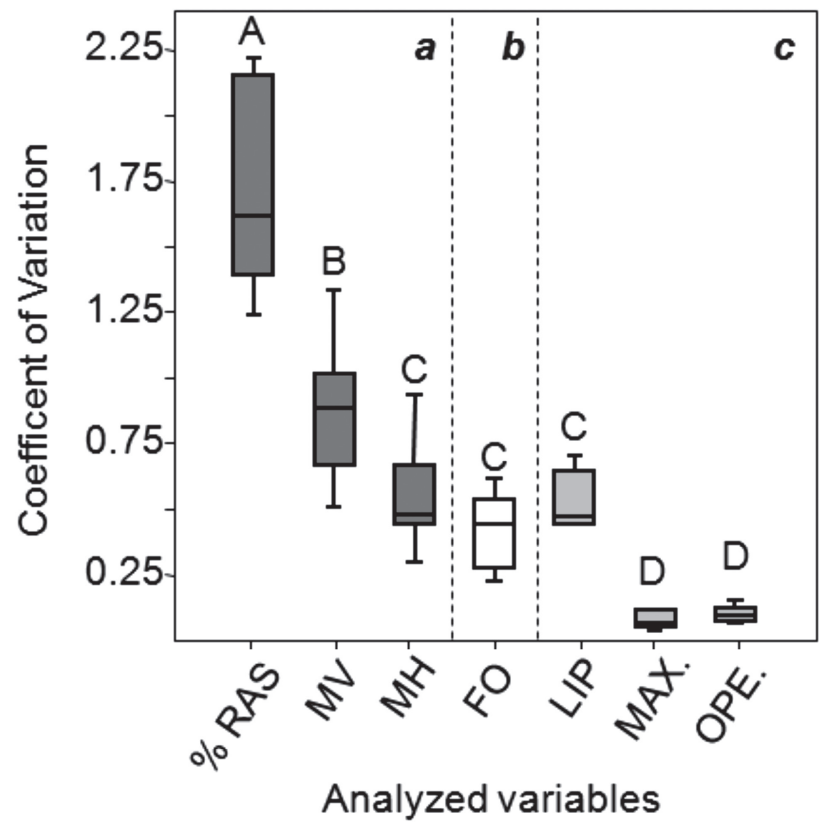

Fig. 5. Comparisons of plasticity among behavioral (a), respiratoy (b) and morphological traits (c) of Piaractus mesopotamicus as measured by the coefficient of variation (CV) across the DO gradient. Capital letters above box plots indicate groups in multiple comparison Tukey's tests after a one way ANOVA. Names of traits as defined in the text.

\section{Discussion}

Our results showed that Piaractus mesopotamicus is capable to modify quickly morphological, behavioral and respiratory variables, displaying an integrated strategy to respond to the stress produced by an oxygen poor environment. Among morphological variables, we observed the development of three different traits in response to hypoxia: lower lip, the anterior border of maxillary and the opercular valve. The lip protuberance of $P$. mesopotamicus 
was similar to that reported in a previous study (Saint-Paul \& Bernardinho, 1988), consisting of an expansion of the dermal tissues of lower jaw on the horizontal plane with two rounded anterolateral lobes. This structure generates a change in mouth orientation that allows the contact of the mouth with the water surface in a lesser body inclination angle, facilitating continuous swimming during ASR. Additionally, it prevents the mixing of the inspired oxygenated surface water with deoxygenated water from below. Maxillary development was observed recently in other characids (Scarabotti et al., 2011) and could help preventing the ingress of less oxygenated water through the mouth corners placed more distant to the surface during ASR.

Development of opercular valve during hypoxia is reported for the first time in the present study. Larger opercular valves could allow a wider abduction of opercula whereas valves remain closed, enhancing the negative pressure inside the oral cavity during inspiration. The decrease in pressure within the oral cavity produces an increase in the water flow during each respiratory cycle. The increase in respiratory frequency and tidal volume is a widely used strategy to improve oxygen uptake during hypoxia for many fishes, but the relative importance of the two processes differ among species (Kalinin et al., 1996; Rantin \& Kalinin, 1996; Florindo et al., 2006). In P. mesopotamicus gill hyperventilation is achieved mainly by augmenting the tidal volume, which is an energetically more efficient strategy than the increment in ventilatory frequency (Kalinin et al., 2000). The plastic development of opercular valve could represent an adaptation to improve the performance of this strategy.

Previous laboratory studies observed protuberance development for shorter experimental periods (Saint-Paul \& Bernardinho, 1988), which hindered the determination of the velocity for the complete process and the degree of development of this trait. In our study, all studied dermal structures showed significant increases in a period of three or six hours (depending on the trait), and showed little or no changes between six and nine hours, indicating that the maximum development was reached within this period. Reversion process was almost two-fold faster than development, occurring fully between one and three hours. This information allowed us to establish for the first time the velocity of the plastic response, the time needed for full development, and the difference among minimum and maximum phenotypic values, which are basic descriptors of the phenotype-environment relationship (Schlichting \& Pigliucci, 1998). At histological level, gills of Carassius carassius and C. auratus, can exhibit a great degree in plasticity with complete development of lamellae in the very short term of six hours (Nilsson et al., 2012) showing that the velocity and reversibility are a common characteristic of plastic responses to hypoxia.

The developmental velocity of plastic traits is a key aspect, because the delay time in response to the environment affects severely the costs of the response
(Padilla \& Adolph, 1996; Utza et al., 2014). In floodplain environments inhabited by P. mesopotamicus, DO vary widely in the course of the day. Oxygen concentrations can drop rapidly in the order of $1 \mathrm{mgL}^{-1} \cdot \mathrm{h}^{-1}$, mainly in the afternoon when photosynthesis ceases (Val, 1996; AlmeidaVal et al., 1999). Then, the adaptive value of plastic response is largely dependent of the capacity of the fish to follow the rapid changes in the environment with the development and reversion of morphological structures.

Most of morphological, behavioral and the respiratory traits analyzed in this study showed a logistic reaction norm. This indicates that they are threshold traits exhibiting a rapid development below a critical DO concentration. The main threshold which determines this kind of responses is the critical DO concentration to which a fish without access to the surface cannot maintain their normal oxygen uptake. For P. mesopotamicus this value was determined in respirometric tests as $1.75 \mathrm{mgL}^{-1}\left(34\right.$ torr at $25^{\circ} \mathrm{C}$ ) (Rantin et al., 1998). Before reaching this value, we observed an increase in the respiratory frequency together with the development of opercular valve, which were triggered at similar critical values of 2.30 and $2.70 \mathrm{mgL}^{-1}$ respectively. As stated above, these two functionally related traits allow an increase in ventilatory volume and the rate of oxygen uptake. This is a compensatory response to obtain the little oxygen available in the water column. Below $1.75 \mathrm{mgL}^{-1}$, fish are obligated to find an alternative source of $\mathrm{DO}$, generally recurring to the oxygen available in the surface water by mean of ASR (Kramer \& Mehegan, 1981). In our study, behaviorally and morphological responses occurred at the similar critical DO values, performing ASR and exhibiting lip protuberances and maxillary development around $1.00 \mathrm{mgL}^{-1}$. The coincidence of lip development and ASR is expectable because they are mutually dependent traits: the utility of the protuberances depend on the occurrence of ASR and the performance of the later is enhanced by the first. These data support the hypothesis that dermal protuberances are traits functionally related to ASR. In this way, different groups of functionally related behavioral and morphological traits are activated in different situations respect to the critical DO concentration.

Previous field studies on lip protuberances observed high variation in morphological response to hypoxia (Braum \& Junk, 1982; Winemiller, 1989; Scarabotti et al., 2009). This variability was attributed to intrapopulation variability, spatial heterogeneity in DO and to small errors in DO measurements near the critical concentration. Our results showed that variation in morphology increased around the critical value and diminished both below and above this value. Other morphological traits with logistic reaction norms can exhibit similar pattern of variation when small measurement error exists (Del Giudice, 2006). Given the small dimension of experimental aquaria and the continuous calibration of the instruments, we exclude the spatial variation of DO and measurement errors as potential explanations of variability. Considering that the reaction norm is logistic, we postulate that small differences in critical values among the 
individuals could generate large differences in the response value at DO near the critical. As individuals were reared in similar conditions during several weeks in laboratory and the state at the moment of experiments was good, differences in the physiological state of the individuals are not expectable. Then, genetic differences in threshold values are a possible explanation of the phenomenon for our results, although we cannot discard additional factors to explain the variability patterns observed in field studies.

Analysis of comparative plasticity demonstrated that ASR was the more plastic trait, followed by morphological and respiratory traits, supporting the hypothesis that behavior is more plastic than morphology (Relyea, 2001; West-Eberhard, 2003). Behavior is a highly reversible, short-term response and incorrect behavioral decisions can be quickly corrected (Relyea, 2001). Fish can exhibit high flexibility in the use of ASR and can adjust their response when perceiving aerial predation risk (Kramer et al., 1983). Morphological responses are more slowly reversible because involve the development of structures, their cost of production is generally higher and can reduce the performance of other functions. Differences in plasticity among morphological traits can be associated, among other factors, to their developmental limits. As protuberances are edematous structures, its final size depends on the preexistent volume of dermal tissue in the plastic organs. We consider that the possibilities for dermal tissue accumulation without interference in other functions are more limited in the opercular valve and in maxillary than in lower lip. However, the relative plasticity of maxillary and lower lip can differ among species with different mouth morphologies (Scarabotti et al., 2011) suggesting that selective forces can modify the degree of plasticity of different traits to optimize the performance of ASR.

\section{Acknowledgements}

We thank to Antonio Frutos for logistical support to acquire and maintain experimental individuals; Andrea Rossi, who provided some reactives for experiments; Mirta Campana, who helped with fish care in laboratory; and Federico Giri who critically read the manuscript. Financial support was provided by an undergraduate fellowship of the Consejo Interuniversitario Nacional (CIN) to M. A. Fernández-Osuna and by the Consejo Nacional de Investigaciones Científicas y Técnicas (CONICET) to P. A. Scarabotti.

\section{References}

Almeida-Val, V. M. F., A. R. Chippari Gomes \& N. P. Lopes. 2006. Metabolic and physiological adjustments to low oxygen and high temperature in fishes of the Amazon. Pp. 443-500. In: Val, A. L., V. M. F. Almeida-Val \& D. J. Randall (Eds.). Fish Physiology: Heidelberg: Elsevier.
Almeida-Val, V. M. F., A. L. Val \& I. Walker. 1999. Long- and short-term adaptation of Amazon fishes to varying $\mathrm{O}_{2}$ levels: intraspecific phenotypic plasticity and interspecific variation. Pp. 185-206. In: Val, A. L. \& V. M. F. Almeida-Val (Eds.). Biology of Tropical Fishes. Manaus, INPA.

Anjos, M. B., R. R. de Oliveira \& J. Zuanon. 2008. Hypoxic environments as refuge against predatory fish in the Amazonian floodplains. Brazilian Journal of Biology, 68: 45-50.

Branson, B. A. \& P. Hake. 1972. Observations on an accessory breathing mechanism in Piaractus nigripinnis (Cope) (Pisces, Teleostomi, Characidae). Zoologischer Anzeiger Leipzig, 189: 292-297.

Braum, E. \& W. J. Junk. 1982. Morphological adaptation of two Amazonian characoids (Pisces) for surviving in oxygen deficient waters. Internationale Revue der gesamten Hydrobiologie, 67: 869-886.

Chapman, L. J., J. S. Albert \& F. Galis. 2008. Developmental plasticity, genetic differentiation, and hypoxia-induced tradeoffs in an african cichlid fish. The Open Evolution Journal, 2: $75-88$.

Chapman, L. J., L. S. Kaufman, C. A. Chapman \& F. E. McKenzie. 1995. Hypoxia tolerance in twelve species of East African cichlids: potential for low oxygen refugia in Lake Victoria. Conservation Biology, 9: 1274-1287.

Chapman, L. J. \& D. McKenzie. 2009. Behavioral responses and ecological consequences. Pp. 25-77. In: Richards, J. G., A. P. Farrell \& C. J. Brauner (Eds.). Hypoxia. San Diego, Elsevier.

Chen, K. Y. \& J. C. Morris. 1972. Kinetics of oxidation of aqueous sulfide by oxygen. Environmental Science \& Technology, 6: 529-537.

Chippari-Gomes, A. R., L. C. Gomes, N. P. Lopes, A. L. Val \& V. M. F. Almeida-Val. 2005. Metabolic adjustments in two Amazonian cichlids exposed to hypoxia and anoxia. Comparative Biochemistry and Physiology, Part B, 141: 347-355.

Cline, J. D. \& F. A. Richards. 1969. Oxygenation of hydrogen sulfide in seawater at constant salinity, temperature, and $\mathrm{pH}$. Environmental Science \& Technology, 3: 838-843.

Del Giudice, M. 2006. Increased residual variance at developmental switch points: statistical artifact or indicator of exposed genotypic influence? Evolution, 60: 192-195.

Domenici P., C. Lefrançois \& A. Shingles. 2007. Hypoxia and the antipredator behaviours of fishes. Philosophical Transactions of the Royal Society B, 362: 2105-2121.

Florindo, L. H., C. A. C. Leite, A. L. Kalinin, S. G. Reid, W. K. Milsom \& F. T. Rantin. 2006. The role of branchial and orobranchial $\mathrm{O}_{2}$ chemoreceptors in the control of aquatic surface respiration in the neotropical fish tambaqui (Colossoma macropomum): progressive responses to prolonged hypoxia. The Journal of Experimental Biology, 209: 1709-1715.

Gibert, P., B. Moreteau, J. R. David \& S. M. Scheiner. 1998. Describing the evolution of reaction norm shape: body pigmentation in Drosophila. Evolution, 52: 1501-1506.

Junk, W. J. 1997. The Central Amazon Floodplain. Ecology of a pulsing system. Heidelberg, Springer-Verlag, 525p. 
Kalinin, A. L., F. T. Rantin, M. N. Fernandes \& M. L. Glass. 1996. Ventilatory flow relative to intrabuccal and intraopercular volumes in two ecologically distinct erythrinids (Hoplias malabaricus and Hoplias lacerdae) exposed to normoxia and graded hypoxia. Pp. 191-202. In: Val, A. L., V. M. F. AlmeidaVal \& D. J. Randall (Eds.). Physiology and biochemistry of the fishes of the Amazon. Manaus, INPA.

Kalinin, A. L., W. Severi, C. D. R. Guerra, M. J. Costa \& F. T. Rantin. 2000. Ventilatory flow relative to intrabuccal and intraopercular volumes in the serrasalmid fish Piaractus mesopotamicus during normoxia and exposed to graded hypoxia. Revista Brasileira de Biologia, 60: 249-254.

Kramer, D. L. 1987. Dissolved oxygen and fish behavior. Environmental Biology of Fishes, 18: 81-92.

Kramer, D. L., D. Manley \& R. Bourgeois. 1983. The effect of respiratory mode and oxygen concentration on the risk of aerial predation in fishes. Canadian Journal of Zoology, 61: 653-665.

Kramer, D. L. \& J. P. Mehegan. 1981. Aquatic surface respiration, an adaptive response to hypoxia in the guppy, Poecilia reticulata (Pisces, Poeciliidae). Environmental Biology of Fishes, 6: 299-313.

Lande, R. 2014. Evolution of phenotypic plasticity and environmental tolerance of a labile quantitative character in a fluctuating environment. Journal of Evolutionary Biology, 27: 866-875.

Leite, C. A. C., L. H. Florindo, A. L. Kalinin, W. K. Milsom, \& F. T. Rantin. 2007. Gill chemoreceptors and cardiorespiratory reflexes in the neotropical teleost pacu, Piaractus mesopotamicus. Journal of Comparative Physiology A, 193: 1001-1011.

Lewis Jr., W. M. 1970. Morphological adaptations of Cyprinodontoids for inhabiting oxygen deficient waters. Copeia, 1970: 319-326.

Morosawa, T. 2011. Hypoxia tolerance of three native and three alien species of bitterling inhabiting Lake Kasumigaura, Japan. Environmental Biology of Fishes, 91: 145-153.

Nilsson G. E., A. Dymowskab \& J. A. W. Stecyk. 2012. New insights into plasticity of gill structure. Respiratory Physiology \& Neurobiology, 184: 214-222.

Oomen, R. A. \& J. A. Hutchings. 2015. Genetic variability in reaction norms in fishes. Environmental Reviews, 23: 353-366.

Padilla, D. K. \& S. C. Adolph. 1996. Plastic inducible morphologies are not always adaptive: The importance of time delays in a stochastic environment. Evolutionary Ecology, 10: 105-117.

Park, I. S., S. J. Park, H. W. Gil, Y. K. Nam \& D. S. Kim. 2011. Anesthetic effects of clove oil and lidocaine- $\mathrm{HCl}$ on marine medaka (Oryzias dancena). Laboratory animals, 40: 45-51.

Pollock M. S., L. M. J. Clarke \& M. G. Dubé. 2007. The effects of hypoxia on fishes: from ecological relevance to physiological effects. Environmental Reviews, 15: 1-14.

Rantin, F. T., C. R. Guerra, A. L. Kalinin \& M. L. Glass. 1998. The influence of aquatic surface respiration (ASR) on cardio-respiratory function of the serrasalmid fish Piaractus mesopotamicus. Comparative Biochemistry and Physiology Part A, 119: 991-997.
Rantin, F. T. \& A. L. Kalinin. 1996. Cardiorespiratory function and aquatic surface respiration in Colossoma macropomum exposed to graded and acute hypoxia. Pp. 169-180. In: Val, A. L., V. M. F. Almeida-Val \& D. J. Randall (Eds.). Physiology and biochemistry of the fishes of the Amazon. Manaus, INPA.

Reid, A. J., M. J. Farrell, M. N. Luke \& M. L. Chapman. 2013. Implications of hypoxia tolerance for wetland refugia use in Lake Nabugabo, Uganda. Ecology of Freshwater Fish, 22: 421-429.

Relyea, R. A. 2001. Morphological and behavioral plasticity of larval anurans in response to different predators. Ecology, 82: 523-540.

Rutjes, H. A. 2006. Phenotypic Responses to Lifelong Hypoxia in Cichlids. Unpublished Ph. D. Dissertation, Leiden University, 168p.

Saint-Paul, U. \& G. Bernardinho. 1988. Behavioural and ecomorphological responses of the neotropical pacu Piaractus mesopotamicus (Teleostei, Serrasalmidae) to oxygen-deficient waters. Experimental Biology, 48: 19-26.

Saint-Paul U. \& G. M. Soares. 1988. Ecomorphological adaptation to oxygen deficiency in Amazon floodplains by serrasalmid fish of the genus Mylossoma. Journal of Fish Biology, 32: 231-236.

Scarabotti, P. A., J. A. López, R. Ghirardi \& M. J. Parma. 2011. Morphological plasticity associated with environmental hypoxia in characiform fishes from neotropical floodplain lakes. Environmental Biology of Fishes, 92: 391-402.

Scarabotti, P. A., M. J. Parma, J. A. López \& R. Ghirardi. 2009. Dermal lip protuberances associated with aquatic surface respiration in juveniles of the piscivorous characid Salminus brasiliensis (Actinopterygii: Characidae). Neotropical Ichthyology, 7: 459-464.

Scheiner, S. M. \& C. J. Goodnight. 1984. The comparison of phenotypic plasticity and genetic variation in populations of the grass Danthonia spicata. Evolution, 4: 845-855.

Schlichting, C. D. \& M. Pigliucci. 1998. Phenotypic evolution: a reaction norm perspective. Sunderland, Sinauer Associates Incorporated, 387p.

Severi, W., F. T. Rantin \& M. N. Fernandes. 1997. Respiratory gill surface of the serrasalmid fish, Piaractus mesopotamicus. Journal of Fish Biology, 50: 127-136.

Sneddon, L. U. 2012. Clinical anesthesia and analgesia in fish. Journal of Exotic Pet Medicine, 21: 32-43.

Soares, M. G. M. \& W. J. Junk. 2000. Respiratory adaptations of five curimatid species (Teleostei, Curimatidae) to oxygen depletation in an Amazonian floodplain lake. Verhandlungen des Internationalen Vereinigung für Theoretische und Angewandte Limnologie, 27: 1063-1069.

Soares, M. G. M., N. A. Menezes \& W. J. Junk. 2006. Adaptations of fish species to oxygen depletion in a central Amazonian floodplain lake. Hydrobiologia, 568: 353-367.

Sundin, L., S. G. Reid, F. T. Rantin \& W. K. Milsom. 2000. Branchial receptors and cardiorespiratory reflexes in a neotropical fish, the tambaqui (Colossoma macroponum). Journal of Experimental Biology, 203: 1225-1239. 
Urbina, M. A., M. E. Forster \& C. N. Glover. 2011. Leap of faith: voluntary emersion behaviour and physiological adaptations to aerial exposure in a non-aestivating freshwater fish in response to aquatic hipoxia. Physiology \& Behavior, 103: 240-247.

Utza, M., J. M. Jeschkeb, V. Loeschckec \& W. Gabriel. 2014. Phenotypic plasticity with instantaneous but delayed switches. Journal of Theoretical Biology, 340: 60-72.

Val, A. L. 1996. Surviving low oxygen levels: lessons from fishes of the Amazon. Pp. 59-53. In: Val, A. L., V. M. F. AlmeidaVal \& D. J. Randall (Eds.). The physiology of tropical fishes. Manaus, INPA.

Weber, J. M. \& D. L. Kramer. 1983. Effects of hypoxia and surface access on growth, mortality, and behavior of juvenile guppies, Poecilia reticulata. Canadian Journal of Fisheries and Aquatic Sciences, 40: 1583-1588.

West-Eberhard, M. J. 2003. Developmental Plasticity and Evolution. Oxford, Oxford University Press, 816p.
Whitman, D. W. \& A. A. Agrawal. 2009. What is phenotypic plasticity and why is it important? Pp. 1-63. In: Whitman, D. W. \& T. N. Ananthakrishnan (Eds.). Phenotypic Plasticity of Insects. Enfield, Science Publishers.

Winemiller, K. O. 1989. Development of dermal lip protuberances for aquatic surface respiration in South American Characid fishes. Copeia, 1989(2): 382-390.

Yamanaka H., Y. Kohmatsu \& M. Yuma. 2007. Difference in the hypoxia tolerance of the round crucian carp and largemouth bass: implications for physiological refugia in the macrophyte zone. Ichthyological Research, 54: 308-312.

Submitted November 17, 2015

Accepted April 01, 2016 by Bernardo Baldisserotto 